\title{
Autonomy-Supportive Leadership Behavior Contents
}

\author{
Zakaria Hocine, Jian Zhang, Yahui Song, Lan Ye \\ Dongling School of Economics \& Management, University of Science and Technology, Beijing, China \\ Email: zakaria.hocine@gmail.com, zhangj67@manage.ustb.edu.cn, 13811899602@163.com, \\ lanyeustb@gmail.com
}

Received 12 April 2014; revised 17 May 2014; accepted 24 May 2014

Copyright @ 2014 by authors and Scientific Research Publishing Inc.

This work is licensed under the Creative Commons Attribution International License (CC BY).

http://creativecommons.org/licenses/by/4.0/

(c) (i) Open Access

\begin{abstract}
Previous research on leader support was mainly based on the theory of social exchange, whereas few empirical studies have been derived from another motivational frame work. This study based on self-determination theory (SDT: Deci \& Ryan) investigated leaders' autonomy-supportive behavior within the organizational context. Leader's autonomy support means from employees' perspectives, providing greater choice, and encouraging self-initiation. Results from a sample of 65 managers working in Chinese enterprises showed four specific leader behaviors, including trust and respect of employees, instructing of employees' career planning, counseling and recognizing, as well as positive monitoring and feedback that may give rise to employees' perceived autonomy support. Discussion focused on the importance of leader's autonomy-supportive behavior and pointed out some prospects for the future research.
\end{abstract}

\section{Keywords}

Leadership, Autonomy Support, Perceived Autonomy Support, Self-Determination Theory

\section{Introduction}

Research on autonomy support mainly focused on leaders within the interpersonal environment. Deci et al. have described autonomy-supportive leaders on the basis of an empirical study as: 1) acknowledging subordinates' perspectives; 2) providing relevant information in non-controlling ways; 3) offering choice; 4) offering positive feedback; 5) encouraging self-inspiration and 6) self-control instead of forcing subordinates to act in a particular way [1]. Gagne and Deci tried to precede training for managers which includes: encouraging subordinates’ initiative, providing non-controlling feedback, acknowledging and accepting subordinates [2]. As a result, they found trainee autonomy support orientation level significance superior than the control oriented group. Subordinates of 
leaders that have received training showed up higher job satisfaction, and more trust to the company management. At the same time, they revealed more correct attitude toward their work.

Deci has defined four kinds of leaders' behaviors: High control (HC), moderate control (MC), moderate autonomy support (MA), and high autonomy support (HA). Deci used a scale including the four kinds of solutions to leaders to choose the appropriate one in order to distinguish their behaviors (e.g. Kim is a working staff for several years). He is working with colleagues. In recent weeks, however, he is always preoccupied and listless. He is doing his work with less energy than usual. Being Kim's supervisor, the most appropriate way: 1) put pressure on him and ask him to increase his job rhythm (MC); 2) ask him and help him to come up with his listless (HA); 3) warning him that if he keeps slow working rhythm, he will assume some punitive measures (HC); let him make a comparison on work efficiency with other colleagues (MA) [3].

The componential theory of creativity proposes that positive behaviors of supervisors include serving as a good work model, planning and setting goals appropriately, supporting the work group within the organization, communicating and interacting well with the work group, valuing individual contributions to the project, providing constructive feedback, showing confidence in the work group, and being open to new ideas [4]. Amabile has found seven kinds of leadership behaviors that have significant effects on employee's perceived support through the work diary, namely 1) Supporting — Positive; showing support for a team member's actions or decisions, helping alleviate stressful situations for subordinates, socializing, and keeping team members informed about stressful issues and addressing subordinates' negative feelings 2) Monitoring-Positive; maintaining regular contact with and providing general guidance to subordinates, providing constructive positive feedback on work done, monitoring progress in a timely manner, reacting to problems in the work with understanding and help, and absence of an expected negative or alteration of a negative pattern; 3) Recognizing-Positive; recognizing good performance in private and in public; 4) Consulting-Positive; acting on subordinates' ideas or wishes, asking for team members' ideas and opinions; 5) Clarifying Roles and Objectives; creating high time pressure with assignments, giving assignments that are not appropriate for the team member, not providing enough clarity about an assignment, changing assignments or objectives too frequently, and assignments that conflict with other management instructions; 6) Monitoring-Negative checking on the status of assigned work too often, inadequate understanding of subordinates' capabilities or work, providing no constructive negative feedback on work done checking on the status of assigned work for too long, and displaying lack of interest in subordinates' work or ideas; and 7) Problem Solving - Negative; avoiding solving problems or even creating problems. The first four behaviors had a significantly positive relationship with subordinate ratings of leader support, whereas the latter three had a significantly negative relationship with subordinate ratings of leader support [5].

At present, the study of the influence of leader's autonomy support on subordinates is still a difficult question within research in human resource management and organizational behavior. Previous research materials were based on social exchange theory, which explored perceived organizational support, perceived supervisor support, and emphasized the relationship between supervisor and employees benefits. Based on social exchange theory, perceived organizational support and perceived supervisor support research were carried out under the logical framework of support-reward. Support inspired by reward is a kind of extrinsic motivation; in this process the employee is passive, and controlled. This kind of empowerment mechanism is completely different from self-determination theory's principles of autonomy-supportive managerial style. SDT considers that autonomy support excitation is innate, constructive to integration of self-consciousness; this is a kind of intrinsic motivation. All driven behaviors of employees by both strength and duration will increase the extrinsic motivation. Thus, the two concepts are similar but their meaning is different, and their mechanism of effects is different too.

Deci has defined four different types of behaviors of leaders, but did not point out universal types of autonomy-supportive behavior contents in the practices of management; Amabile cited manager's daily types of behavior, but did not divide those behaviors according to different styles. The present research is integrating the concept of autonomy-support at the organizational level. It is following the instructions of self-determination theory, figures out the specific contents of autonomy-supportive leadership behaviors and strives for innovation in management.

\section{Research Method}

This paper was made on the basis of the existing review of the literature of autonomy-supportive managerial styles, findings and achievements analyzes that we induce to understand the nature of autonomy-supportive leadership. In addition; we used interview and questionnaire surveys to find out the specific contents of autonomy- 
supportive leadership behavior.

\subsection{Interview Process}

The use of interviews is mainly important to understand closely managers' nature and subordinates' perceptions of autonomy support, define the concept of autonomy support in management of enterprises, as well as summarize the specific contents of autonomy-supportive leadership behavior.

Usually before starting an interview, researchers collect and read relevant literature to outline the interview process. According to Yukl management practices mainly included; planning and organizing, counseling, work recognition, reward, emotional support, and problem solving [6].

\subsubsection{Interview Sample Selection}

Following a typical sampling method, four managers and four employees were interviewed. Managers' sample included managers from longest time of exercise of the profession (12 years) and shortest ones (nearly 2 years). These managers held management roles in different departments. Employees sample, included work experience ranging from 2 to 7 years. Employees were serving state-owned enterprises, private enterprises and foreign enterprises in lowest-level positions. These eight research samples representativeness were best whether from age, gender and educational background or from their engagement in the profession and time of practice.

Managers' sample: 1) He Nansheng, male, 28 years old, owns a master's degree, serves a state-owned enterprise as an engineering department project manager for more than one year; 2) Guan Peiyun, male, 35 years old, owns a bachelor's degree, serves a foreign enterprise as a director of the commerce department for more than 5 years; 3) Zhao Xiaole, male, 38 years old, owns a bachelor's degree, serves a private enterprise as a sales manager for more than 10 years; and 4) Li Yuan, female, 40 years old, owns a bachelor's degree, serves a foreign telecommunication company as a director of Human Resources for more than 7 years.

Employees' sample: 1) Wang Cun, female, 27 years old, owns a master's degree, serves a state-owned enterprise as a the industry design engineer for her second year; 2) Han Wei, female, 24 years old, owns a college degree, serves a private enterprise accounting department for more than 4 years; 3) Hu Hongwei, male, 32 years old, owns a bachelor's degree, serves a foreign enterprise as a testing engineer for more than 7 years; and 4) Wen Jing, male, 29 years old, owns a master's degree, serves a foreign enterprise as a program development engineer for more than 3 years.

\subsubsection{Interviews Conduct}

According to a self-designed sample of management practices survey and interview outline, researcher pursued structured interviews with eight research samples from December 20th to 28th, 2013. Researcher chose a quite restaurant and meeting rooms for the interviews. Interviews durations differed from 60 to 120 minutes using a voice recorder and a note book to note member's feelings in specific moments. Before each interview, the researcher introduced his identity and research perspectives. Because of the familiarity of the researcher about the sample contents, members showed positive and coopering during the conversations, as they were very interested in the topic of the research and hoped to share the research results as soon as possible. The researcher was very graceful for their trust, and had carefully discussed the question of autonomy support according to the research perspectives for a better consideration of the issue. As well as, examined every word they spoke and every behavior they showed.

\subsubsection{Arrangement and Analysis of Interviews Data}

According to the interview outline about autonomy support related contents, the researcher arranged both the words and the meanings of the interviews, made a generic analysis, and finally got the nature of the contents of autonomy supportive leadership.

\subsection{Survey Process}

\subsubsection{Questionnaire Sample Selection and Description}

Based on the principle of random sampling and convenience sampling combination of samples from Beijing, Wuhan, Tianjin, Hebei, Changsha, Chengdu and other regions, we released autonomy-supportive leadership questionnaire. We distributed 98 copies of the questionnaire, recycled 86 questionnaires, with a percentage of $88 \%$. 
We altogether recycled 65 valid questionnaires. Valid samples from 65 leaders various demographic characteristics descriptions and results (see Table 1) showed that: the sample fits the requirement of our present topic, because both state-owned enterprises and private ones represented an average of more than $50 \%$. Samples average level of educational background was relatively high. Thus, research on autonomy support understanding is relatively thorough.

\subsubsection{Measurement Tools}

In this research, measurement were gotten through both the review of the literature and interviews to gather autonomy-supportive leadership contents items; using encoding techniques to construct the structure of autonomy-supportive leadership behaviors. Through many times of measurement of questionnaire survey of corporate leaders; we have made "autonomy-supportive leadership scale.” A confirmatory factor analysis was applied using structural equation that showed high reliability and validity of "Autonomy-supportive leadership measurement scale" based on psychological measurement. The scale contains mainly the measurement contents, including 20 items divided into 4 dimensions: counseling and work recognition, trust and respect, employee career planning instructing, and positive monitoring and feedback.

\section{Results}

\subsection{Interview Results}

After the interviews, the researcher had found employees paying particular attention to managers counseling and work recognition, trust and respect, career planning instructing, and positive monitoring and helpful feedback.

\subsubsection{Counseling and Work Recognition}

Both managers and subordinates agree that counseling and timely work recognition can enhance subordinates' perceived autonomy support. When we questioned subordinates about manager's initiative to invite subordinates to discuss together the work process, determine the changes of plans, and allow them to develop their own subjective initiatives and comment, subordinates showed strong perceived autonomy support and feel valued. Certainly, sometimes due to the nature of work (e.g. Project-oriented tasks) managers must be strict in accordance with the project plan, and whenever a problem occurs, they will often solve the problem directly according to their own experience and will not counsel their subordinates' opinions. In regard of this point, employees were also very

\section{Table 1. Leaders' sample information.}

\begin{tabular}{|c|c|c|c|c|}
\hline Characteristics & Classification & $\mathrm{N}$ & Ratio & Percentage \% \\
\hline \multirow{2}{*}{ Gender } & Female & 29 & $44.60 \%$ & $44.60 \%$ \\
\hline & Male & 36 & $55.40 \%$ & $100 \%$ \\
\hline \multirow{4}{*}{$\begin{array}{l}\text { Educational } \\
\text { Background }\end{array}$} & College & 12 & $18.50 \%$ & $18.50 \%$ \\
\hline & Undergraduate & 29 & $44.60 \%$ & $63.10 \%$ \\
\hline & Master & 20 & $30.80 \%$ & $93.80 \%$ \\
\hline & Doctor & 4 & $6.20 \%$ & $100 \%$ \\
\hline \multirow{3}{*}{ Age } & Less than 30 & 2 & $3.10 \%$ & $3.10 \%$ \\
\hline & 30 to 40 & 37 & $56.90 \%$ & $60 \%$ \\
\hline & More than 40 & 26 & $40 \%$ & $100 \%$ \\
\hline \multirow{6}{*}{ Years of work } & Less than 5 years & 1 & $1.50 \%$ & $1.50 \%$ \\
\hline & 5 to 10 & 7 & $10.80 \%$ & $12.30 \%$ \\
\hline & 10 to 20 & 34 & $52.30 \%$ & $64.60 \%$ \\
\hline & 20 to 30 & 22 & $33.80 \%$ & $98.50 \%$ \\
\hline & More than 30 years & 1 & $1.50 \%$ & $100 \%$ \\
\hline & State-owned enterprises & 27 & $41.50 \%$ & $41.50 \%$ \\
\hline \multirow{2}{*}{ Enterprises } & Private enterprises & 29 & $44.60 \%$ & $86.20 \%$ \\
\hline & Foreign companies & 9 & $13.80 \%$ & $100 \%$ \\
\hline
\end{tabular}


understandable, and did not show negative resentments about it. An example from the sample (Wen Jing) stressed: "After all working does not mean studying, if something went wrong when we have to cut down the schedule of a project, generally the boss will deal with it directly depending on his own knowledge.

Concerning work recognition, there exist differences of understanding manager's recognition manner among employee. Wang Cun said: "when I met my leader in private, he evaluated my recent work and said (e.g. you did a good job). I was happy to hear those words because originally I thought that he does not recognize my efforts, and after this his recognition of my work my incentives for work doubled." However, Han Wei shook his head and said: "giving verbal praise does not mean leader's sincere appreciation; it is a kind of appearance of assentation feeling. It is only recommended in public occasions, such us the praise in front of the whole department. That is where the employee will feel real recognition of his work. In addition to the verbal praise, a unique recognition of their work does not only allow employees to bear more important roles and responsibilities, but also encourage them and raise their perceived autonomy support." Wen Jing indicated her point of view saying: "I think if my boss identifies my job performance, this will be reflected on my next project task through the distribution of tasks phase. If my boss gives me greater risk module, responsibility, I will be more excited to work and turn pressure into motivation, but it is still difficult to get the chance to be appreciated."

\subsubsection{Trust and Respect}

When managers respect their subordinates' way of doing things and trust their ability to do their work, subordinates perceived autonomy support will also double. Wang Cun was confused and complained saying: "I hope that when my superior assigns me a task, he just need to tell me what kind of results he is waiting for, rather than telling to do so or so from time to another. I do not know what value I should highlight in this work." Some managers (leaders) would casually ask employees to do things in their own ways, otherwise in one hand; employees will be greatly limited in term of playing space; on the other hand, employees will feel that their managers do not trust their working abilities.

\subsubsection{Instructing Employees Career Planning}

On one hand, managers would help employees to analyze the value and the significance of their work positions. On the other hand, they will guide employees' future career development and prospects.

Most interviewed managers and employees think that targeted career development planning and work opportunities, including career advancement and job rotations, can inspire employees, particularly through the work of their superiors to help them recognizing the value and the meaning of their current job. In such cases, employees are likely to show more visible perceived autonomy support. Hu Hongwei said: "I often after a working day feel very confused and do not know what exactly this feeling of boring at work brings to the meaning of my life; the current job gives me the feeling of being left alone and confused, which seems to have no meaning for me. Even though, sometimes my leader discusses with me my future development arrangements, but I still have the same negative feelings." When it came to employees own positions, Director Li Yuan said: "When asking about every encountered turnover reason for leaving, the vast majority of employees feel that their own positions are below their expectations, and cannot be able to understand the real value of those jobs. They often do not have any particular personalized career planning for their future development, which make it difficult to help them for better work positioning, and find them new directions according to personal efforts to reduce their perceived confusion.”

\subsubsection{Positive Monitoring and Feedback}

Employees agreed that leaders regular monitoring and inspection of their work progress and quality as well as informational feedback improve their sense of autonomy support. Hu Hongwei said: "After the inspection of the superior, subordinates with mediocre performance would appreciate leaders' initiative to seek improvements, which would help them to stimulate their enthusiasm for work.” Project Manager Pei Yun said: "when subordinates relationships are in disharmony and experience conflicts, leader should deal with conflicts in constructive manner and actively create a good atmosphere, because he always worry about subordinates task tardiness or quality substandard, and frequently ask subordinates about job completion.”

\subsection{Survey Results}

This research employed confirmatory factor analysis to test autonomy-supportive leadership valid samples validity and reliability (see Figure 1). Results (see Table 2 ) of the goodness of fit showed: $\mathrm{P}=0.052, \chi^{2} / \mathrm{df}=1.36<$ 


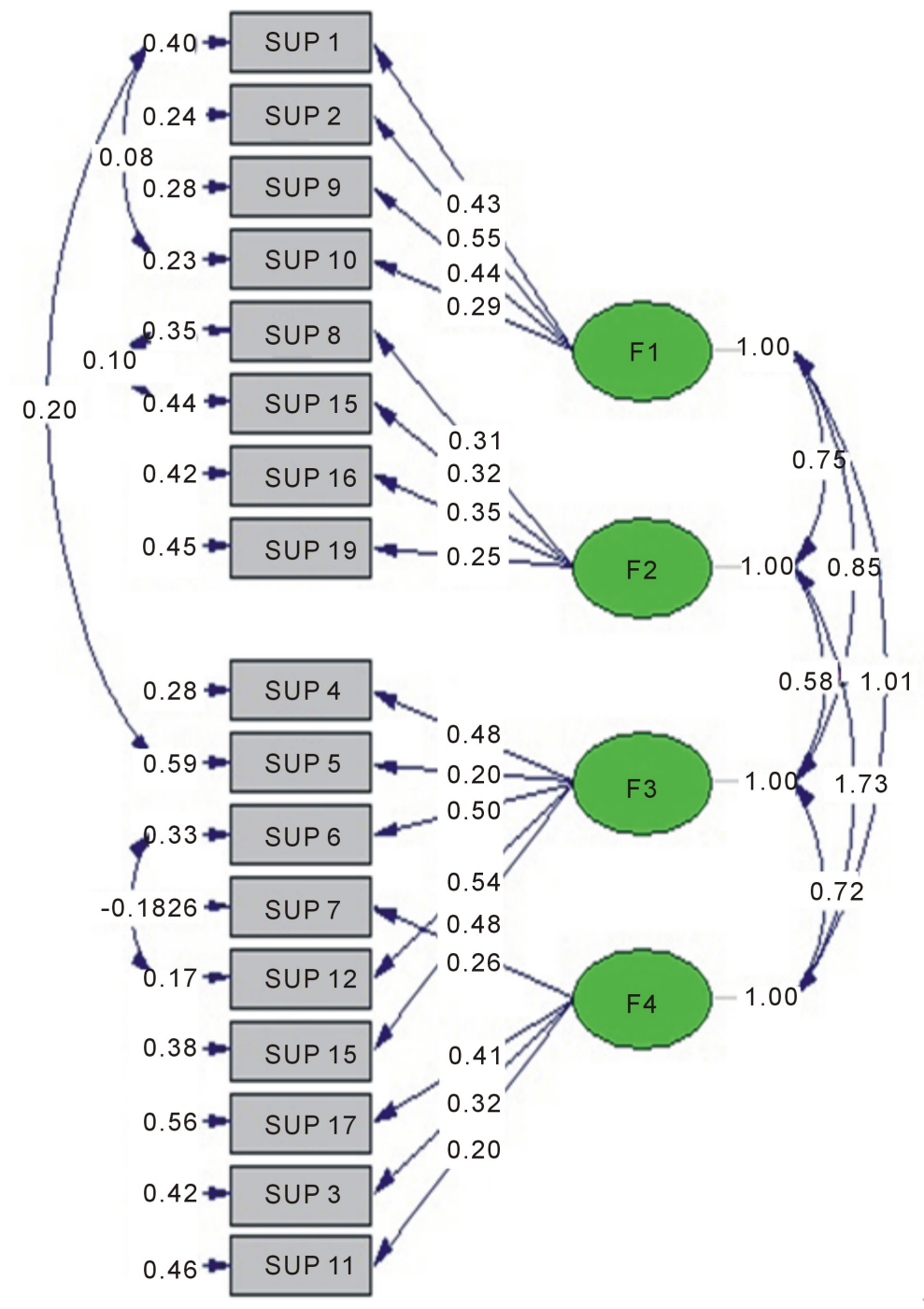

Figure 1. Autonomy-supportive leadership confirmatory factor model.

Table 2. Autonomy-supportive leadership scale fit indicator statistics.

\begin{tabular}{cccccc}
\hline$\chi^{2} / \mathrm{df}$ & NNFI & IFI & CFI & RMSEA & $\alpha$ \\
\hline 1.36 & 0.89 & 0.91 & 0.90 & 0.054 & 0.845 \\
\hline
\end{tabular}

3 , NNFI $=0.89, \mathrm{IFI}=0.91, \mathrm{CFI}=0.90$ were greater than $0.8, \mathrm{RMSEA}=0.054<0.08$. All the indicators are in line with the requirements of this research. This indicates that the survey fits well. Alpha coefficients for each dimension were respectively $0.816,0.749,0.845,0.734$ (greater than 0.7 ), which means that the reliability is very good.

Autonomy-supportive leadership measurement scale is divided into four dimensions:

(F1) Counseling and work recognition refers to managers' invitation of their employees to discuss work issues and together determine change and solution to problems. Whenever employees make outstanding achievements managers are likely to express their gratitude and recognition of their efforts and achievements through various channels.

(F2) Trust and respect refers to managers' assignment of tasks to employees. Carefully trust their employees' ability to do task and respect of their own way in of doing things and solving problems, which may confer more autonomy.

(F3) Instructing employees career planning refers to managers' explanation of the meaning and the value of 
work for both organization and employee himself, point out future development opportunities, and put forward some suggestions for employees career planning.

(F4) Positive monitoring and feedback refers to managers regularly supervision and checks for employees' job completion, keeping the objective of timely guidance and giving constructive feedback.

\section{Discussion and Recommendations}

Autonomy is a key construct in SDT [7]. Autonomy-supportive leadership behavior constitutes the main important aspects of interpersonal environment of autonomy support. It has been revealed that managers conducted emotional regulation, periodic inspection and feedback, counseling, problem solving within organizations. These aspects provide employee great sense of autonomy support. The present paper revealed some specific contents of autonomy-supportive leaders' behavior mainly by counseling and recognizing employees work, trust and respect to employees, career planning instructing, and positive monitoring and feedback, which raise significantly employees perceived autonomy support.

During the interview process, we recognized that employees pay particular attention to their career planning development and future, especially the young employees. Thus, managers are asked to instruct employees' career planning, and provide them some suggestions that may weaken their confusions at work to enhance their confidence and passion to work, especially when employees are not interested in the tasks. Managers should listen to employees' complaints periodically to deal with their negative emotions. At the same time, managers need to emphasize employees' development; value and significance that employees' tend to reposition their own work role, and produce greater enthusiasm for work.

Research has shown that mangers are likely to show grateful recognition of employees' job performance in both public and private. However, according to this research, when employees demonstrate excellent performance, managers should provide them more task responsibilities and challenge to let them will feel reuse, show more when given opportunities, make more efforts at work and seeking new ways to work creatively, solve problems and willing to perform better. Work recognition does not only enhance the sense of autonomy support among employees, but also rise their willing for improvement in a positive process.

Employees expect to gain a good feeling of a real teamwork atmosphere if leaders allow them to be part of the problem solving process and let them express their own opinions and views at work. Although sometimes employees recommend the presence of their leaders to notice their work achievements and give importance to their feelings from time to another. Moreover, informational positive feedback when discussing with employees is essential.

\section{Conclusion}

In the context of the corporate in its different characteristics, autonomy-supportive leadership is mainly reflected in counseling and work recognition, career development opportunities, regulatory guidance and feedback, and emotional trust and respect. Through these four aspects, leaders are likely to provide support for employees, which let them acquire strong perception of autonomy support.

\section{Acknowledgements}

We especially thank the National Science Foundation of China (70771009, 71071017) and the Fundamental Research Funds for the Central Universities (FRF-BR-09-019) for supporting this research.

\section{References}

[1] Gagne, M. and Deci, E.L. (2005) Self-Determination Theory and Work Motivation. Journal of Organizational Behavior, 26, 331-362. http://dx.doi.org/10.1002/job.322

[2] Deci, E.L., Spiegel, N.H., Ryan, R.M., et al. (1982) Effects of Performance Standards on Teaching Styles: Behavior of Controlling Teachers. Journal of Educational Psychology, 74, 852-859. http://dx.doi.org/10.1037/0022-0663.74.6.852

[3] Deci, E.L., Connell, J.P. and Ryan, R.M. (1989) Self-Determination in a Work Organization. Journal of Applied Psychology, 74, 580-590. http://dx.doi.org/10.1037/0021-9010.74.4.580

[4] Amabile, T.M. (1997) Motivating Creativity in Organizations: On Doing What You Love and Loving What You Do. California Management Review, 40, 39-58. 
http://dx.doi.org/10.2307/41165921

[5] Amabile, T.M., Schatzel, E.A., Moneta, G.B. and Kramer, S.J. (2004) Leader Behaviors and the Work Environment for Creativity: Perceived Leader Support. The Leadership Quarterly, 15, 5-32. http://dx.doi.org/10.1016/j.leaqua.2003.12.003

[6] Yukl, G.A. (2002) Leadership in Organizations. 5th Edition, Prentice Hall, Upper Saddle River.

[7] Gange, M. and Bhave, D. (In Press) Autonomy in the Workplace: An Essential Ingredient to Employee Engagement and Well-Being in Every Culture. In: Chirkov, R. and Sheldon, Eds., Personal Autonomy in Cross-Cultural Context: Perspective on the Psychology of Freedom and People's Well-Being, Springer.

\section{Appendix : Autonomy-Supportive Leadership Behavior Measurement Scale}

1) When your subordinates encounter difficult problems, you will discuss with them the problem causes and find solution to solve the problem together.

2) You will regularly (weekly or monthly) check the work progress and qualities of subordinates and give suggestions to improve their work situation.

3) When subordinates performance is mediocre, you will take the initiative to help them to seek improvement methods of their performance and stimulate their enthusiasm for work.

4) When the work process needs to be changed, you will take the initiative to invite the relevant subordinate to negotiate and determine the change of the plan together.

5) You will take the initiative to grant subordinates with sufficient degree of autonomy to allow them to face work problems.

6) In case your subordinates show work tardiness, you will be understanding and helping their attitude with guidance.

7) You will listen carefully to your subordinates during work complaints and negative emotions, and help them to carry out self-regulation.

8) When subordinates are not interested in the contents of work, you will patiently tell the work value and significance.

9) When subordinates are depressed and anxious, you will take the initiative to ask and help them to deal with their troubles.

10) When subordinates relationship is in disharmony and/or experiencing conflicts, you will deal with their conflicts constructively (in a constructive manner) and actively create a good atmosphere.

11) Except at work, you will take the initiative to promote your friendly feelings to subordinates by telephone or email etc.

12) When your subordinates make outstanding achievement, you will praise him publically.

13) When your subordinates make a special contribution, you will be sincerely grateful for their efforts.

14) You always worry about your subordinates task tardiness or quality substandard, and frequently ask them about job completion.

15) You will listen to your subordinates' views on their personal career development prospects

16) You will provide your subordinates regularly with guidance and advices for work development plan.

17) You will take the initiative to provide more job opportunities to improve subordinates work ability.

18) You will check subordinates work completion at any time and do not give any evaluation for their work performance.

19) When work tasks are distributed, you will fully believe your subordinates have the ability to do the tasks.

20) You will respect your subordinate's choice and problem solving way. 